\title{
Extraction of Palladium from Acidic Chloride Media into Emulsion Liquid Membranes Using LIX 984N-C ${ }^{\circledR}$
}

\author{
Satit Praipruke ${ }^{1}$, Korbratna Kriausakul ${ }^{2 *}$, Supawan Tantayanon ${ }^{2,3}$ \\ ${ }^{1}$ Program of Petrochemistry, Faculty of Science, Chulalongkorn University, Bangkok, Thailand \\ ${ }^{2}$ Green Chemistry Research Laboratory, Department of Chemistry, Faculty of Science, Chulalongkorn University, \\ Bangkok, Thailand \\ ${ }^{3}$ National Center of Excellence for Petroleum, Petrochemicals and Advanced Materials (NCE-PPAM), Bangkok, \\ Thailand \\ Email: *korbratna.k@chula.ac.th
}

Received May 12, 2012; revised June 20, 2012; accepted July 11, 2012

\begin{abstract}
The extraction of palladium from hydrochloric acid solutions into emulsion liquid membranes (ELMs) using LIX $984 \mathrm{~N}-\mathrm{C}$ as the extractant was investigated. The influential factors and the total capacities of palladium extraction were determined by a batch method. The behavior of palladium extraction by ELMs under the operational conditions- $\mathrm{pH}$ of the external feed phase, surfactant and extractant concentration, internal stripping phase concentration, treat ratio and agitation speed were reported. Using LIX 984N-C, palladium was effectively extracted from the external acidic chloride feed phase into the internal receiving phase of W/O emulsions. More than $92 \%$ of palladium could be extracted at a feed $\mathrm{pH}$ of 2 with 3\% Span 80, 9\% LIX 984N-C and 7M HCl at a stirring speed of $300 \mathrm{rpm}$.
\end{abstract}

Keywords: Palladium Extraction; LIX 984N-C; Emulsion Liquid Membrane

\section{Introduction}

Recently, much attention has been paid on the development of an efficient treating process for industrial wastes because they have a probability of destroying the global environment $[1,2]$. Palladium, one of the precious group metals (PGMs) is a major pollutant from the chemical industry which utilizes palladium as catalysts as well as electrical and corrosion resistant materials. Solvent extraction is a common hydrometallurgical process for the recovery of palladium from most industrial plants. The studies of palladium extraction using pyridinecarboxamides [3], thiosulfate, ACORGA ${ }^{\circledR}$ CLX50 [4], hexadecylpyridinium [5], phosphonium [6], $\mathrm{NH}_{4}{ }^{+}$-dibenzyldiaza18-crown-6 [7], Cyanex 471 [8], hydroxyoxime [9], Cyanex 301-immobilized material [10], $\alpha$-benzoin-oximes and Cyphos $^{\circledR}$ IL/toluene [11], imidazolium nitrate immobilized resin [12] as extractants have been reported. However, the metal extraction rates by solvent extraction are generally low and the inventories of the organic solvent and metal extractant are substantial for the separation process. Emulsion liquid membranes (ELMs) [13], on the other hand a promising technology for the separation of heavy metal ions from aqueous effluent streams, has re-

"Corresponding author. moved the limitations of solvent extraction by combining extraction and stripping in a single operation. The reduction of metal concentration in the feed stream can be achieved to very low level. The treatment of aqueous streams contaminated with palladium by ELMs using a bi-functional surfactant has been reported [14,15]. In recent years, Cognis Inc. [16] has introduced oxime derivatized extractants for copper, such as LIX 63, LIX 65, LIX 84I-C, LIX 860N-IC and LIX 984N-C, showing faster kinetics, easier phase disengagement and stronger copper extraction. A combination of salicylaldoximes with extractive strength and fast kinetics and ketoximes with proven excellent physical performance and stability led to the development of LIX 984N-C, which was found to effectively extract copper from aqueous acidic medium $[17,18]$. With similar coordination chemistry of palladium with phenolic oxime ligands to that of copper [19], this gives an insight for the use of LIX 984N-C for palladium extraction.

In the present work, the extraction of palladium from aqueous hydrochloric acid medium containing a low concentration of palladium (10 ppm) by ELMs using LIX $984 \mathrm{~N}-\mathrm{C}$ as an extractant is carried out. The behavior palladium extraction and optimum operating condition by ELMs are also investigated. 


\section{Experimental}

\subsection{Reagents}

The chemical structures of the carrier (extractant) and the surfactant are used in this study. The carrier, LIX 984N-C obtained from Cognis Ireland is an equi-volume mixture of LIX 860N-IC (5-nonyl salicylaldoxime) and LIX 84I-C (2-hydroxy-5-nonyl-acetophenone-oxime) (Figure 1(a)) in a high flash point hydrocarbon diluent and used as such. Emulsifier, Span 80 (sorbitan monooleate) (Figure 1(b)) was supplied by Kao Industrial, Thailand. The commercial extractant and surfactant were used as received. The organic solvent, Exxol ${ }^{\mathrm{TM}}$ D80 (dearomatized aliphatic hydrocarbon), supplied by ExxonMobil Chemical (Thailand) Co., Ltd., was used as the membrane material.

\section{2. [Pd(II)-LIX 984N-C] Complex Formation}

Equivalent volumes (20 mL) of aqueous acidic feed solution ( $\mathrm{pH}$ 2) containing $10 \mathrm{ppm}$ of $\mathrm{Pd}(\mathrm{II})$ and the organic phase of LIX 984N-C in Exxol D80 were allowed to contact each other for $60 \mathrm{~min}$ at room temperature (30 \pm $1^{\circ} \mathrm{C}$ ). After gravitational settling the aqueous and organic phases were separated for analyses. A Perkin-Elmer model AAnalyst 100 AAS was used to determine the Pd(II) concentration in the aqueous portion. UV spectra of Pd(II) in aqueous feed solution were recorded before and after the extraction process. [Pd(II)-LIX 984N-C] complex in the organic phase was also identified by a UV spectrometer equipped with a deuterium-halogen light source DH 2000 and USB 2.0 fiber optic model USB4000 UVVIS detector.

Carrier<smiles>[R10]CCC(CCCC)Oc1ccccc1/C=N\O</smiles>

(a)

Surfactant

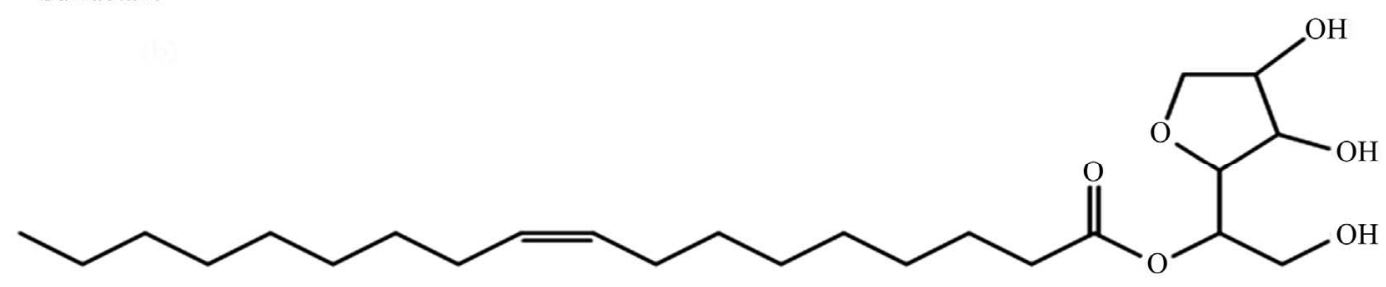

Span 80

(b)

)

\subsection{Pd(II) Extraction into ELMs}

Batch extractions were conducted in a glass-mixer-settler (7” dia.) fitted with baffles, a stop-cock for easy sampling and a variable speed $30 \mathrm{~mm}$ turbine impeller. The primary W/O emulsion was prepared by gradually dripping $\mathrm{HCl}$ solution into the oil phase in a beaker using a high speed homogenizer (IKA, Ultra Turrax model T10 basic) at 12,000 rpm for about $30 \mathrm{~min}$. The resultant milky white emulsion was then dispersed into the aqueous feed phase containing $10 \mathrm{ppm}$ Pd(II) using a turbine mixer at 250 to $300 \mathrm{rpm}$. Samples were drawn at fixed intervals (5 min.) and the emulsion and aqueous phases were allowed to settle in measuring test tubes. The concentration of $\mathrm{Pd}(\mathrm{II})$ in the aqueous phase was determined by standard procedures using Perkin-Elmer model AAnalyst 100 AAS. The parametric variation of the components in the external aqueous feed phase, the membrane phase and internal aqueous phase are described in Table 1.

Palladium extraction into ELMs is represented by $C_{e} / C_{e 0}$ as a function of time, where $C_{e}$ is the instantaneous concentration and $C_{e 0}$ is the initial concentration of palladium in the external aqueous feed solution.

\section{Results and Discussion}

\section{1. [Pd(II)-LIX 984N-C] Complex Formation}

The UV spectra of Pd(II) in aqueous solution that a prominent peak at $244 \mathrm{~nm}$ with a maximum absorbance of 0.84 indicates the initial $\mathrm{Pd}(\mathrm{II})$ in the aqueous phase (Figure 2(a)) and after extraction the absorbance was reduced to 0.17 with a broadening of the peak (Figure 2(b)). The<smiles>CCCCC1C(O)/C(=N/O)c2ccccc2C1CCC</smiles>

LIX 84I-C 
Table 1. Parametric variation of the components in the external aqueous feed phase, the membrane phase and internal aqueous phase for Pd(II) extraction by ELMs.

\begin{tabular}{|c|c|c|}
\hline Parameters & Range used & Remarks \\
\hline External aqueous feed phase $\left(W_{I I I}\right)$ & $V_{e}=300 \mathrm{~mL}$ & \\
\hline (a) palladium concentration & $C_{e}=10 \mathrm{ppm}$ & \\
\hline (b) with buffer $\mathrm{pH}$ & $\mathrm{pH}=1-3$ & Adjusted pH by hydrochloric solution \\
\hline Oil Membrane phase $\left(O_{I I}\right)$ & $V_{m}=25 \mathrm{~mL}$ & \\
\hline (a) solvent & Exxol D80 & De-aromatized aliphatic hydrocarbon \\
\hline \multirow[t]{2}{*}{ (b) carrier } & LIX 984N-C ${ }^{\circledR}$ & \\
\hline & $C_{c}=5-12 \mathrm{wt} \%$ & \\
\hline \multirow[t]{2}{*}{ (c) surfactant } & Span 80 & \\
\hline & $C_{s}=2.5-3.5 \mathrm{wt} \%$ & \\
\hline Internal aqueous phase & $V_{i}=25 \mathrm{~mL}$ & \\
\hline \multirow[t]{2}{*}{ (a) stripping acid } & $\mathrm{HCl}$ & \\
\hline & $C_{i}=3-7 \mathrm{M}$ & \\
\hline Treat ratios & $T_{r}=0.125-0.250$ & \\
\hline Agitation speed & $250-350$ rpm & \\
\hline The ratio of the phases & $1: 1$ & The emulsion is water-in-oil (W/O) type \\
\hline
\end{tabular}
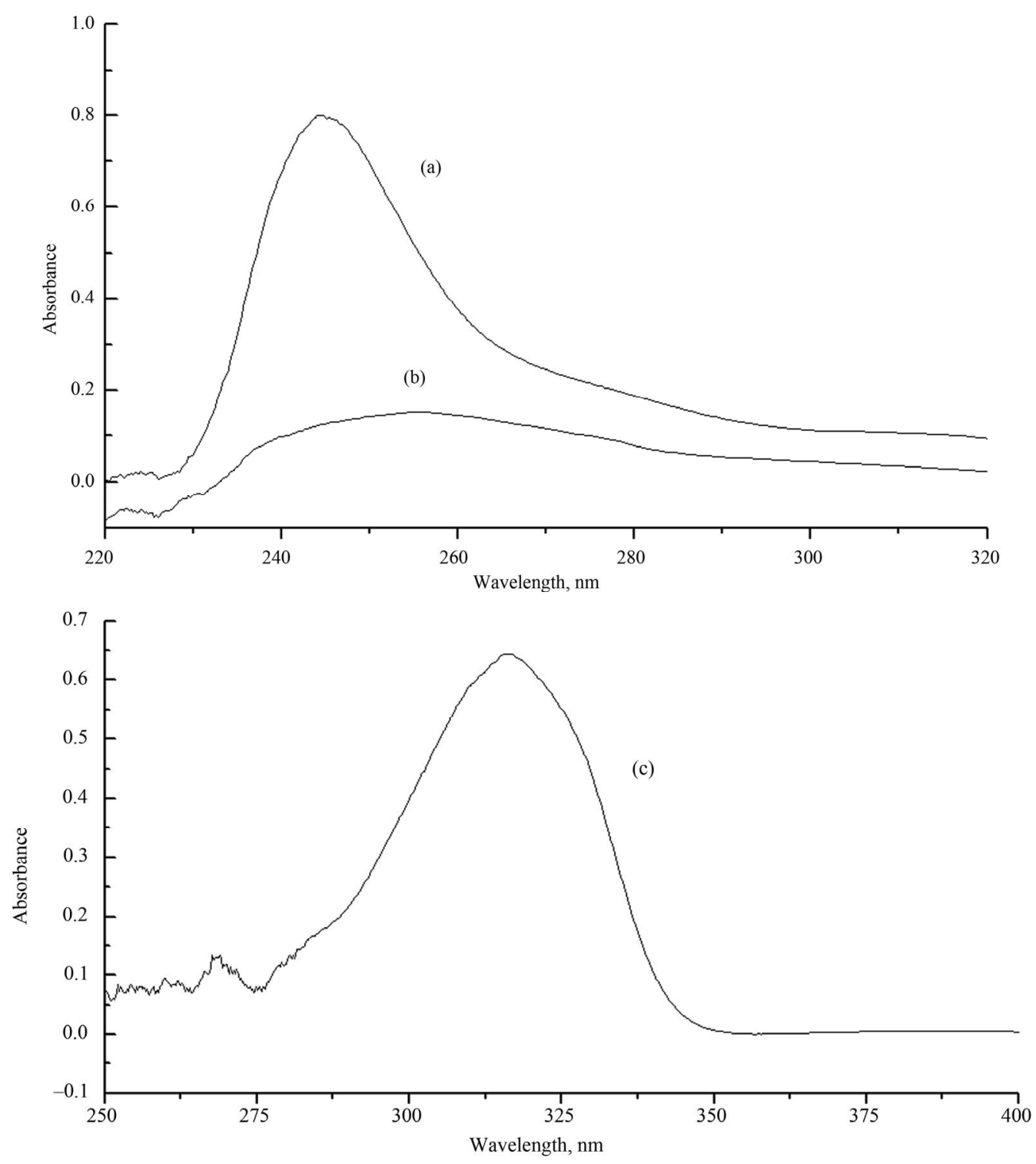

Figure 2. UV absorption spectra (a) Palladium in feed solution before extraction; (b) Palladium after extraction and (c); [Pd(II)-LIX 984N-C] complex in organic phase. 
presence of the [Pd(II)-LIX 984N-C] complex in the organic phase [20] was evident by the prominent peak at $319 \mathrm{~nm}$ with an absorbance of 0.65 (Figure 2(c)).

\subsection{Permeation of Pd(II) through ELMs}

When the W/O emulsion is dispersed in the feed phase, several emulsion globules are formed generating a large surface area for the interfacial reactions and mass transfer. Palladium exists mainly as $\mathrm{Pd}^{2+}$ ions in an external feed solution containing hydrochloric acid with a low $\mathrm{H}^{+}$ion concentration. At the interface of an emulsion globule and the feed phase the following reaction takes place, leading to a formation of a $\mathrm{PdR}_{2}$ complex in the organic phase:

$$
2 \mathrm{HR}_{\text {(org.) }}+\mathrm{Pd}^{2+}{ }_{\text {(aq.) }} \square \quad \mathrm{PdR}_{2 \text { (org.) }}+2 \mathrm{H}^{+} \text {(aq.) }
$$

where HR represents the carrier in the organic phase. The $\mathrm{PdR}_{2}$ complex diffuses through the organic membrane phase to the inner stripping phase, where the $\mathrm{Pd}^{2+}$ ion gets stripped from the carrier into the internal phase of emulsion droplets by the following chemical reaction:

$$
2 \mathrm{H}^{+}{ }_{\text {(aq.) }}+\mathrm{PdR}_{2 \text { (org.) }} \square \quad \mathrm{Pd}^{2+}{ }_{\text {(aq.) }}+2 \mathrm{HR}_{\text {(org.) }}
$$

This type of carrier facilitated transport mechanism has been recognized already as a counter transport $[21,22]$ as schematically shown in Figure 3.

The counter transport mechanism for Pd(II) extraction by ELMs is confirmed by the result of the $\mathrm{Pd}^{2+}$ and $\mathrm{H}^{+}$ concentration in the external feed phase, shown in Table 2. A depletion of palladium concentration in the external aqueous feed solution from 10.00 to $1.742 \mathrm{ppm}$ and a simultaneous fall of $\mathrm{pH}$ from 2.00 to 1.75 were found to take place during the 60 minutes of extraction.

\subsection{Effect of Parametric Variations on Palladium Extraction}

In all experimental runs, the internal phase volume fraction of the extracting emulsion was 1:1 and initial palladium

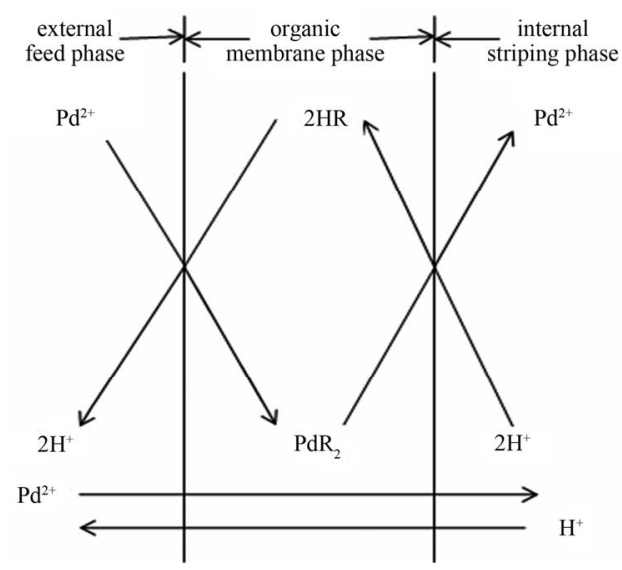

Figure 3. Schematic diagram of permeation mechanism of Pd(II) with ELMs.
Table 2. $\mathrm{Pd}(\mathrm{II})$ and $\mathrm{H}^{+}$concentration in the feed solution during extraction process by ELMs.

\begin{tabular}{ccccc}
\hline \multirow{2}{*}{ Run } & Time (min) & $\mathrm{pH}$ & \multicolumn{2}{c}{ Concentration } \\
\cline { 4 - 5 } & & & $\mathrm{Pd}(\mathrm{II}), \mathrm{ppm}$ & $\mathrm{H}^{+}$ \\
\hline 1 & 0 & 2.00 & 10.00 & 0.010 \\
2 & 5 & 1.93 & 5.397 & 0.012 \\
3 & 10 & 1.89 & 4.629 & 0.013 \\
4 & 15 & 1.86 & 4.007 & 0.014 \\
5 & 20 & 1.85 & 3.291 & 0.014 \\
6 & 25 & 1.83 & 3.199 & 0.015 \\
7 & 30 & 1.78 & 2.821 & 0.017 \\
8 & 35 & 1.77 & 2.373 & 0.017 \\
9 & 40 & 1.77 & 2.243 & 0.017 \\
10 & 45 & 1.77 & 1.995 & 0.017 \\
11 & 50 & 1.75 & 1.908 & 0.018 \\
12 & 55 & 1.75 & 1.745 & 0.018 \\
13 & 60 & 1.75 & 1.742 & 0.018 \\
\hline
\end{tabular}

concentration $\left(C_{e 0}\right)$ in the external feed phase $10 \mathrm{ppm}$. Other operating parameters were varied to study their effect: surfactant concentration, $C_{s}(2.5-3.5 \mathrm{wt} \%)$; external feed $\mathrm{pH},(1-3)$; carrier LIX 984N-C concentration, $C_{\mathrm{c}}$ (3 - $\left.12 \mathrm{wt} \%\right)$; internal acid concentration, $C_{i}(3-7 \mathrm{M})$; agitation speed (250 - $300 \mathrm{rpm})$ and treat ratio, $T_{r}(1: 4$ $1: 8)$. The amount extracted at any time was expressed as a ratio of the instantaneous concentration to initial concentration of palladium $\left(C_{e} / C_{e 0}\right)$.

\subsubsection{Effect of Surfactant Concentration}

The influence of surfactant concentration in the membrane phase of the emulsion on the extraction rates was investigated at a concentration range of $2.5 \%$ to $3.5 \%$ Span 80 by weight. Figure 4 indicates significant increase in the initial extraction rate within 5 minutes, due to a low surface tension of the membrane phase, resulting in small-sized emulsion droplets, allowing faster mass transfer for palladium extraction. A low concentration of Span $80(2.5 \%)$ renders the membrane weak and the emulsion became unstable. Increasing the concentration of Span 80 (3.5\%) enhances mass transfer resistance due to the increase in viscosity of the membrane phase [17]. Both results led to lower total extraction efficiency. With $3.0 \%$ Span 80 by weight maximum palladium extraction could be achieved. Therefore, the surfactant concentration of 3.0\% was chosen for further studies.

\subsubsection{Effect of the Carrier Concentration}

The effect of LIX 984N-C concentration was studied in the range of $5 \%$ to $12 \%$ by weight of the membrane phase at an external feed $\mathrm{pH}$ of 2, while maintaining all other operating conditions constant. Figure 5 shows an increase in the initial rate and total amount extracted with increasing carrier concentration from $5.0 \%$ to $9.0 \%$ by 


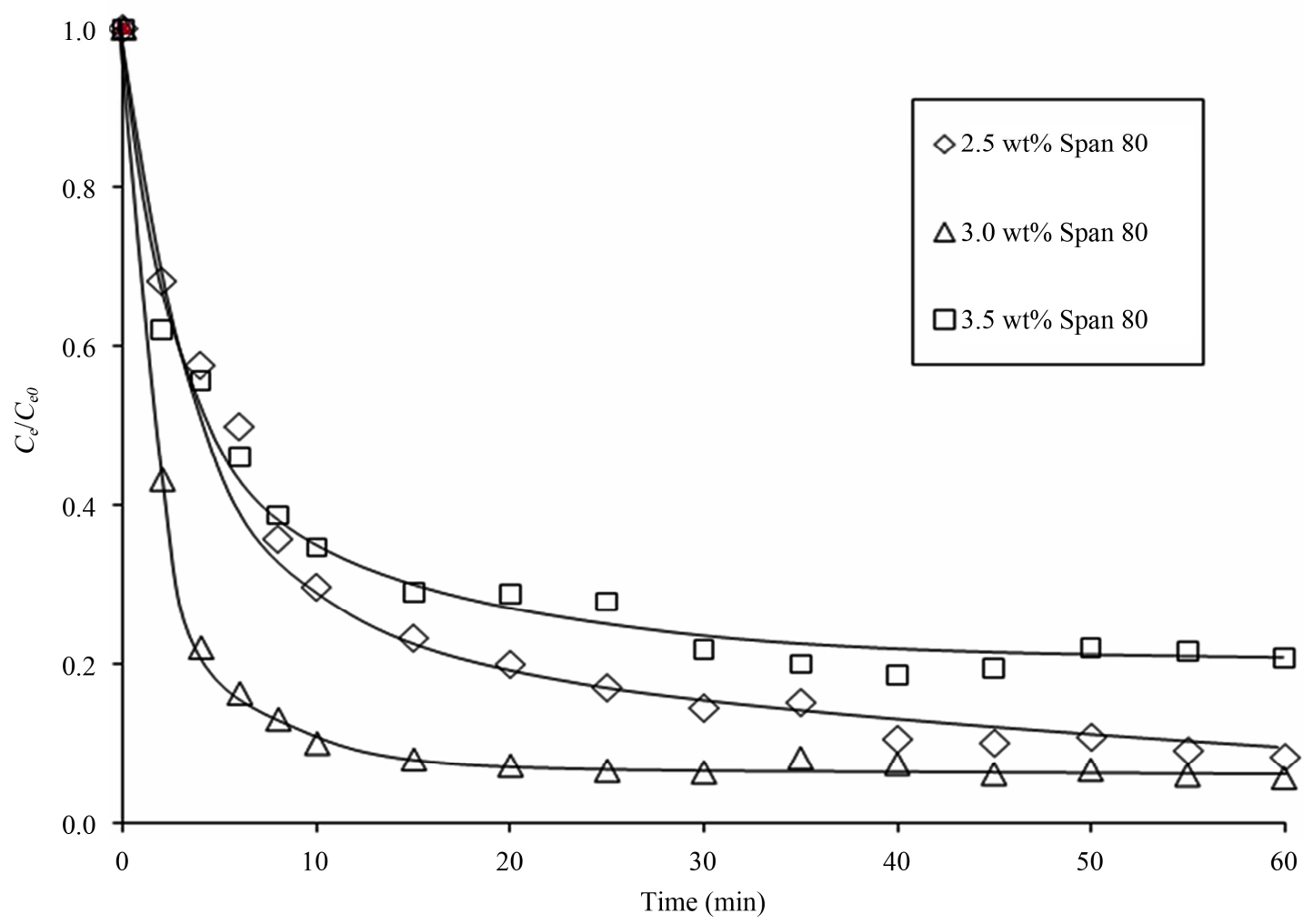

Figure 4. Effect of surfactant concentration on palladium extraction.

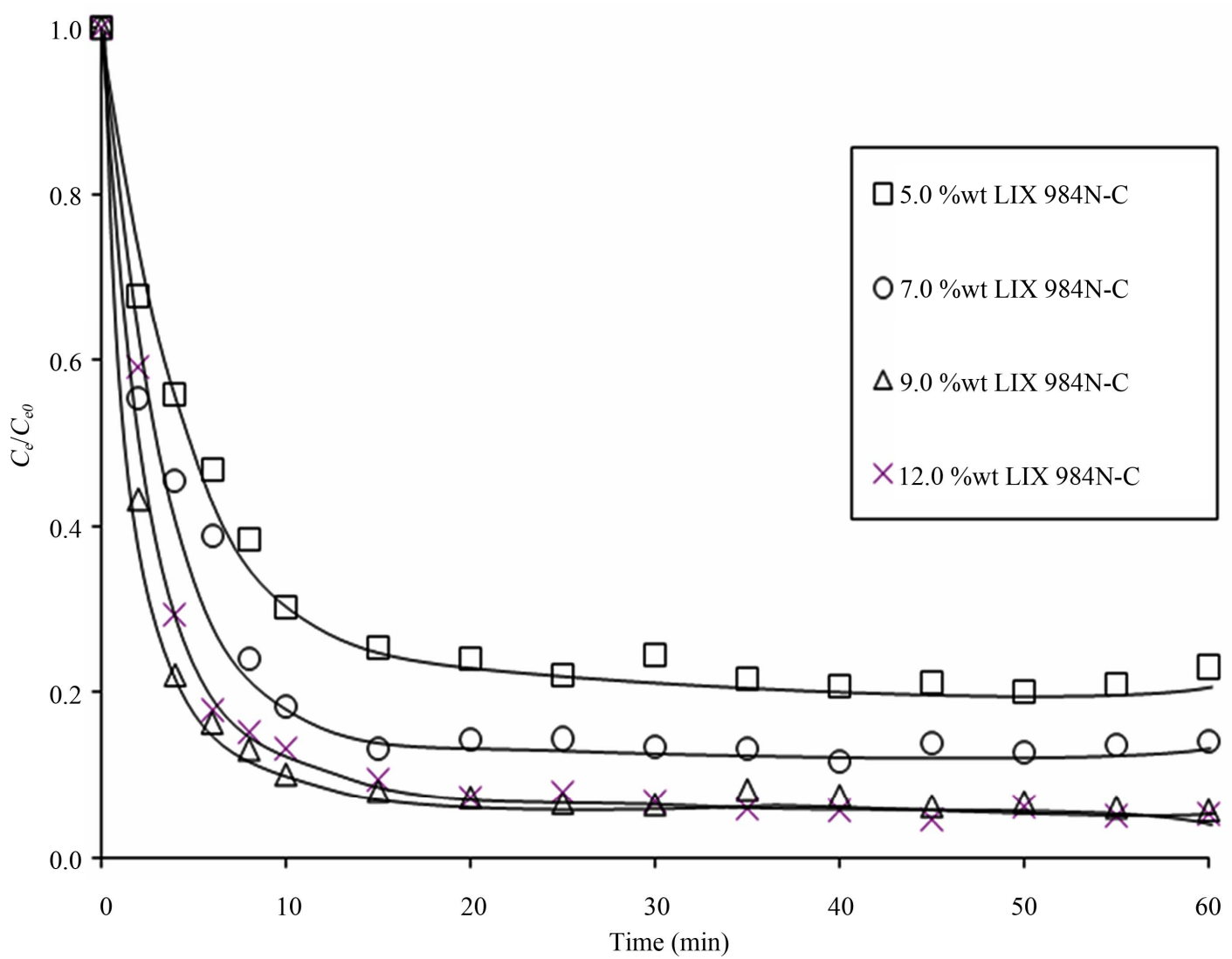

Figure 5. Effect of LIX 984N-C concentration on palladium extraction. 
weight. Increasing the carrier concentration in the membrane phase phenomenologically increases the interfacial solute concentration and hence the driving force for the extraction leading to a high extraction rate [18]. Further increasing the LIX $984 \mathrm{~N}-\mathrm{C}$ concentration to $12 \%$ by weight did not show any change and the final amount extracted remains the same. This demonstrates that changing the carrier concentration does not change the final equilibrium conditions of the system, but affects how fast the equilibrium is reached. Moreover, the carrier acts as a thinner at high concentration due to the higher viscosity in the membrane phase leading to enhanced stability of the emulsion $[21,22]$. Therefore, the carrier concentration of $9.0 \%$ was used to form the W/O emulsion.

\subsubsection{Effect of Acid Concentration in the Internal Stripping Phase}

The experiments were conducted with $\mathrm{HCl}$ concentrations of $3 \mathrm{M}, 5 \mathrm{M}$ and $7 \mathrm{M}$ at a phase $\mathrm{pH}$ of 2. From Figure 6, it is evident that both the initial extraction rate and total Pd(II) extraction depend on the stripping acid concentration, increasing with higher $\mathrm{HCl}$ molarity as a result of the difference in $\mathrm{H}^{+}$concentration between the external and internal phases acting as a driving force in the ELM process [23] and the ability of the internal phase for stripping the [Pd(II)-LIX 984N-C] complex at the membrane/internal stripping phase. At $7 \mathrm{M} \mathrm{HCl}$ the chemical reaction was found to be very fast, with the extraction equilibrium being achieved in about 15 minutes. [22], using hydroxyoxime extractant and hydrochloric acid medium, found the stripping of palladium incomplete with hydrochloric acid concentrations below $6 \mathrm{M}$. The optimum concentration for the internal stripping phase regent of $7.0 \mathrm{M} \mathrm{HCl}$ is thus chosen.

\subsubsection{Effect of Feed pH}

The palladium extraction was carried out with the acidity of the external feed solution being adjusted from $\mathrm{pH} 1$ to 3 by hydrochloric acid. Figure 7 indicates that the palladium extraction is strongly $\mathrm{pH}$ dependent. With a feed $\mathrm{pH}$ of 1 and 3, only $10 \%$ of palladium was extracted. However, almost $100 \%$ of palladium could be extracted within 20 minutes at a feed $\mathrm{pH}$ of 2. [18] also found similar behavior for copper extraction at $\mathrm{pH} 1$ and 2 using LIX 984N-C, but with a higher amount extracted and no further change at higher $\mathrm{pH}$.

\subsubsection{Effect of Treat Ratio}

The ratio of the emulsion phase to the external aqueous feed phase, treat ratio $\left(R_{\mathrm{ew}}\right)$, is a measure of the emulsion holdup in the system. Figure 8 shows the extraction behavior for five diffent $R_{\mathrm{ew}}$ values. The rate and amount of palladium extraction were found to increase with the $R_{\mathrm{ew}}$ value during the 25 minutes of contact time. When the

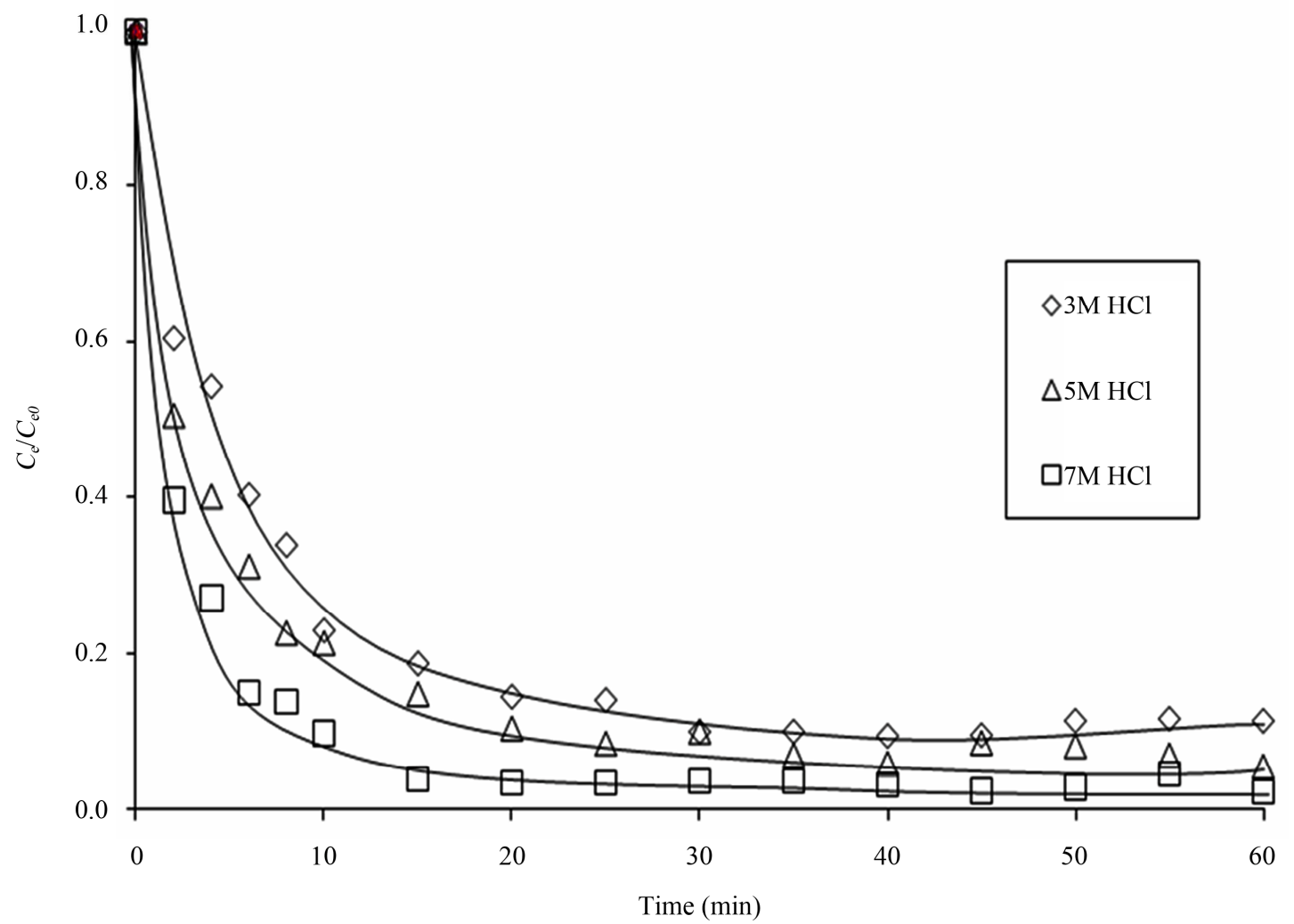

Figure 6. Effect of stripping acid concentration on palladium extraction. 


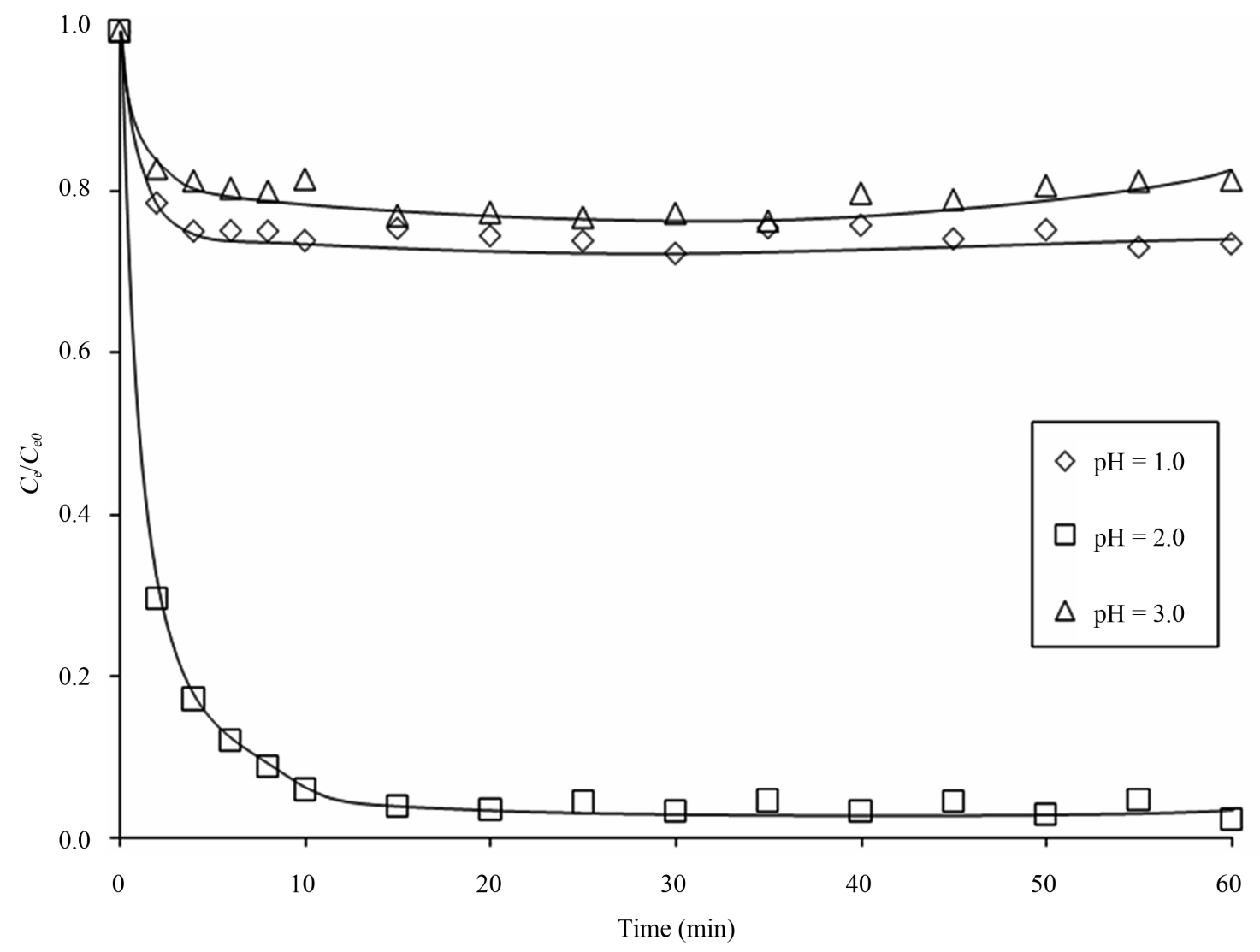

Figure 7. Effect of external feed $\mathrm{pH}$ on palladium extraction.

emulsion holdup is low ( $\left.R_{\mathrm{ew}}=0.125,0.140\right)$, the total amount extracted after 60 minutes was less than $85 \%$. Increasing the emulsion holdup $\left(R_{\mathrm{ew}}=0.200,0.250\right)$, led to larger extent of extraction (92\%), back extraction was later observed due to globule breakage, depicted as a rise in $C_{e} / C_{0}$ versus t curve. With $R_{\text {ew }}$ value of 0.167 the extension behavior was found to be optimal and is chosen for the treat ratio.

\subsubsection{Effect of Agitation Speed}

A proper agitation speed was determined by conducting experiments with a variation of speed from $250 \mathrm{rpm}$ to $350 \mathrm{rpm}$ as shown in Figure 9. The initial rate of palladium extraction was found to increase with increasing agitation speeds from 250 to $350 \mathrm{rpm}$, due to smaller emulsion globules, which provide a larger mass transfer area, forming as a result of the shear force of agitation [24]. Total palladium extraction capacities with agitation speeds of 250 and 275 rpm were less (80\%) than with $300 \mathrm{rpm}$ (92\%). A further increase in the agitation speed to $350 \mathrm{rpm}$, resulted in a decrease of the amount of palladium extracted after 15 minutes with a total extraction of less than $70 \%$. At high agitation speeds the emulsion globules coalesce resulting in enlargement of the globules, indicating two competing processes in the solute transport: the diffusion of the solute through the emul- sion membranes into the internal phase and the leakage of the internal solution due to globule breakage.

\section{Conclusion}

A new efficient carrier, LIX 984N-C, has been introduced for the extraction of palladium from acidic chloride media by an ELM method. A stable W/O emulsion was formulated with $7 \mathrm{M} \mathrm{HCl}$ solution, 3\% Span 80 and 9\% by weight LIX 984N-C in Exxol D80. The behavior of palladium extraction by ELMs under the operational conditions; $\mathrm{pH}$ of the external feed phase, treat ratios and agitation speed were investigated. The feed $\mathrm{pH}$ was found to be the most prominent factor, resulting in the highest initial rate of palladium extraction at a pH of 2 . More than $92 \%$ of palladium could be extracted under the optimum conditions with treat ratio of 1:6 and agitation speed of $300 \mathrm{rpm}$. The permeation mechanism of palladium extraction by ELMs was proved to be counter transport involving a [Pd(II)-LIX 984N-C] complex. It is ascertained that LIX $984 \mathrm{~N}-\mathrm{C}$ allows efficient extraction of dilute palladium solutions by ELMs relative to the conventional solvent extraction method.

\section{Acknowledgements}

The authors would like to thank ExxonMobil Chemical 


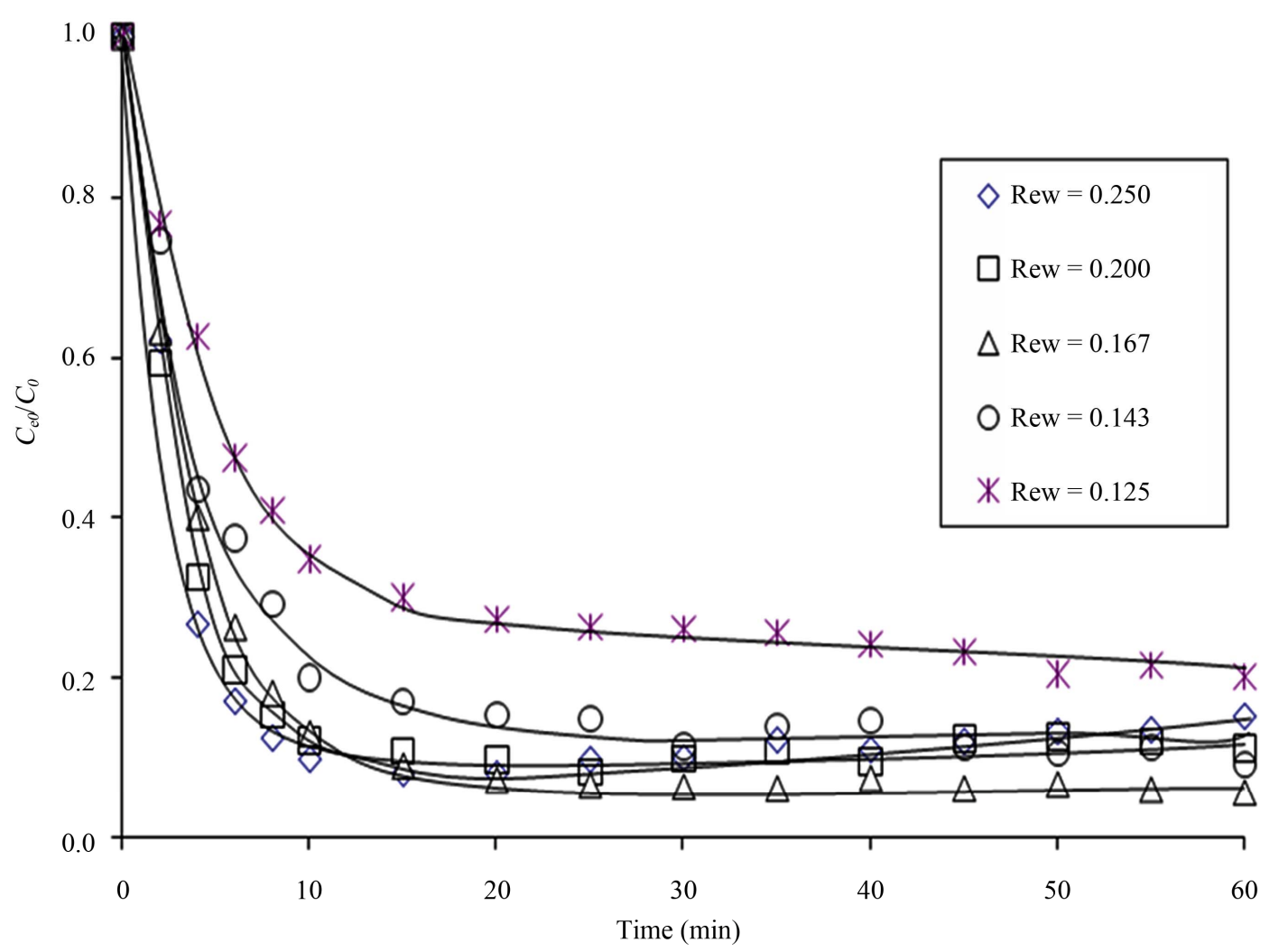

Figure 8. Effect of treat ratio on palladium extraction.

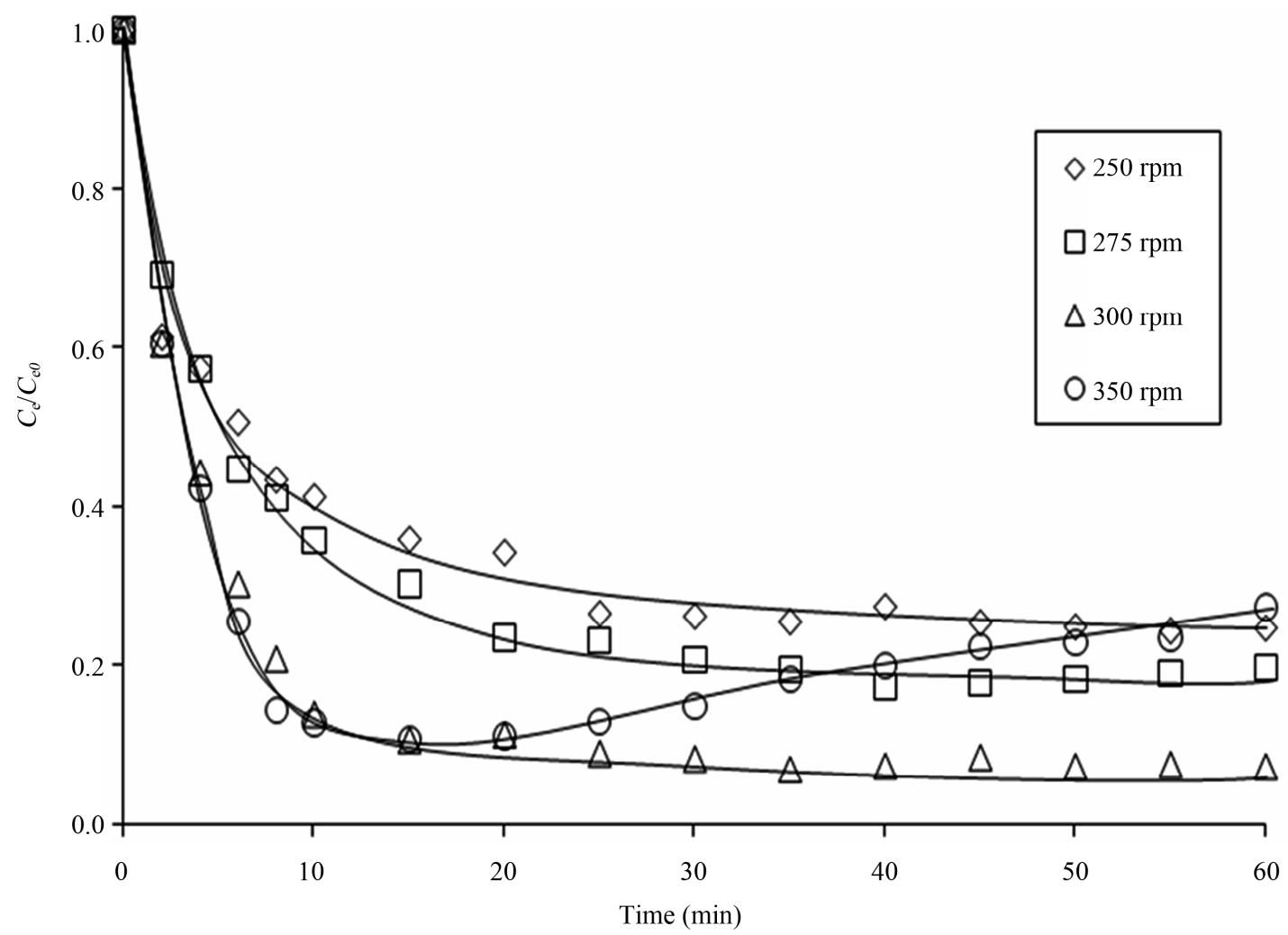

Figure 9. Effect of agitation speed on palladium extraction. 
(Thailand) Limited, Bangkok, Thailand, for the provision kerosene and Cognis Inc., Ireland for the provision of LIX 984N-C ${ }^{\circledR}$ reagents. This work was supported by Program of Petrochemistry and Polymer Science, and National Center of Excellence for Petroleum, Petrochemicals and Advanced Materials (NCE-PPAM), Chulalongkorn University.

\section{REFERENCES}

[1] S. Shen, T. Pan, X. Liu, L. Yuan, Y. Zhang, J. Wang and Z. Guo, "Adsorption of Pd(II) Complexes from Chloride Solutions Obtained by Leaching Chlorinated Spent Automotive Catalysts on Ion Exchange Resin Diaion WA21J," Journal of Colloid and Interface Science, Vol. 345, No. 1, 2010, pp. 12-18.

doi:10.1016/j.jcis.2010.01.049

[2] A. K. Chakravarti, S. B. Chowdhury and D. C. Mukherjee, "Liquid Membrane Multiple Emulsion Process of Separation Copper(II) from Waste Water," Colloids and Surfaces A: Physicochemical and Engineering Aspects, Vol. 166, No. 1-3, 2000, pp. 7-25. doi:10.1016/S0927-7757(99)00452-5

[3] A. Dakshinamoorthy, A. G. C. Nair, S. K. Das, R. K. Singh and S. Prakash, "A Rapid and Selective Separation of Palladium,” Journal of Radioanalytical and Nuclear Chemistry, Vol. 162, No. 1, 1992, pp. 155-162. doi:10.1007/BF02039936

[4] C. Nowottny, W. Halwachs and K. Schugerl, "Recovery of Platinum, Palladium and Rhodium from Industrial Leaching Solutions by Reactive Extractaction," Separation Science and Technology, Vol. 12, No. 2, 1997, pp. 135-144.

[5] G. Khayatian and M. Shamsipur, "Highly Selective and Efficient menbrane Transport of Palladium as Pdcl42Ino Using $\mathrm{NH}^{+}$-Dibenzyldiaza-18-Crown-6,” Separation and Purification Technology, Vol. 16, No. 2-3, 1999, pp. 235-241.

[6] N. Alizadeh, S. Salimi and A. Jabbari, “Transport Study of Palladium through a Bulk Liquid Membrane Using Hexadecylpyridinium as Carrier," Separation and Purification Technology, Vol. 28, No. 3, 2002, pp. 173-180. doi:10.1016/S1383-5866(02)00003-5

[7] I. Szczepanska, A. Borowiak-Resterna and M. Wisniewski, "New Pyridinecarboxamides for Rapid Extraction of Palladium from Acidic Chloride Media," Hydrometallurgy, Vol. 68, No. 1-3, 2003, pp. 159-170.

doi:10.1016/S0304-386X(02)00201-3

[8] C. Fantas, V. Salvado and M. Hidalgo, "Selective Enrichment of Palladium from Spent Automotive Catalysts by Using a Liquid Membrane System," Journal of Membrane Science, Vol. 223, No. 1-2, 2003, pp. 39-48. doi:10.1016/S0376-7388(03)00288-6

[9] E. Guaibal and T. Vincent, "Palladium Recovery from Dilute Effluents Using Biopolymer-Immobilized Extractant," Separation Science and Technology, Vol. 41, No. 11, 2006, pp. 2533-2553.
[10] Z. Hubicki, M. Leszczynska, B. Lodyga and A. Lodyga, "Palladium(II) Removal from Chloride and Chloride-Nitrate Solutions by Chelating Ion-Exchangers Containing N-Donor Atoms,” Mineral Engineering, Vol. 19, No. 13, 2006, pp. 1341-1347. doi:10.1016/j.mineng.2006.01.004

[11] J. H. Brits and D. A. Deglon, "Palladium(II) Stripping rates in PGM Refining,” Hydrometallurgy, Vol. 89, No. 3-4, 2007, pp. 253-259. doi:10.1016/j.hydromet.2007.07.012

[12] M. Regel-Rosocka, M. Wisniewski, A. Borowiak-Resterna, A. Cieszynska and A. M. Sastre, "Selective Extraction of Palladium(II) from Hydrochloric acid Solutions with Pyridinecarboxamides and ACORGA ${ }^{\circledR}$ CLX50," Separation and Purification Technology, Vol. 53, No. 3, 2007, pp. 337-341.

[13] N. N. Li, "Separating Hydrocarbons with Liquid Membranes,” US Patent No. 3410794, 1968.

[14] T. Kakoi, N. Horinouchi, M. Goto and F. Nakashio, "Selective Recovery of Palladium from a Simulated Industrial Waste Water by Liquid Surfactant Membrane Process,” Journal of Membrane Science, Vol. 118, No. 1, 1996, pp. 63-71. doi:10.1016/0376-7388(96)00102-0

[15] T. Kakoi, M. Goto and F. Nakashio, "Separation of Platinum and Palladium(II) by Liquid Surfactant Membranes Utilizing a Novel Bi-Functional Surfactant,” Journal of Membrane Science, Vol. 120, No. 1, 1996, pp. 77-88. doi:10.1016/0376-7388(96)00137-8

[16] Cognis, "Mining Chemicals Technology”. http://www.cognis-us.com/

[17] B. Sengupta, R. Sengupta and N. Subrahmanyam, “Copper Extraction into Emulsion Liquid Membranes Using LIX 984N-C,” Hydrometallurgy, Vol. 81, No. 1, 2006, pp. 67-73.

[18] B. Sengupta, R. Sengupta and N. Subrahmanyam, "Process Intensification of Copper Extraction Using Emulsion Liquid Membranes: Experimental Search for Optimal Conditions,” Hydrometallurgy, Vol. 84, No. 1-2, 2006, pp. 43-53. doi:10.1016/j.hydromet.2006.04.002

[19] A. G. Smith, P. A. Tasker and D. J. White, “The Structures of Phenolic Oximes and Their Complexes," Coordination Chemistry Reviews, Vol. 241, No. 1-2, 2003, pp. 61-85. doi:10.1016/S0010-8545(02)00310-7

[20] A. Dakshinamoorthy and V. Venugopall, "Solvent Extraction Studies on the Complexation of Palladium with Alpha Benzoin Oxime,” Journal of Radioanalytical $\mathrm{Nu}$ clear Chemistry, Vol. 266, No. 3, 2005, pp. 425-429. doi:10.1007/s10967-005-0927-y

[21] E. L. Cussler, D. F. Evan and M. A. Matesich, “Theoretical and Experimental Basis for a Specific Counter Transport System in Membranes,” Science, Vol. 172, No. 3981, 1971, pp. 377-379. doi:10.1126/science.172.3981.377

[22] M. T. A. Reis and J. M. R. Carvalho, "Modelling of Zinc Extraction from Sulphate Solutions with Bis(2-Ethylhexyl) Thiophosphoric Acid by Emulsion Liquid Membranes," Journal of Membrane Science, Vol. 237, No. 1-2, 2004, pp. 97-107. doi:10.1016/j.memsci.2004.02.025 
[23] A. Kargari, T. Kaghazchi and M. Soleimani, "Role of Emulsifier in the Extraction of Gold (III) Ions from Aqueous Solutions Using the Emulsion Liquid Membrane Technique,” Desalination, Vol. 162, 2004, pp. 237-247. doi:10.1016/S0011-9164(04)00047-5
[24] M. V. Rane and V. Venugopal, "Study on the Extraction of Palladium(II) and Platinum(IV) Using LIX 84I," $H y$ drometallurgy, Vol. 84, No. 1-2, 2006, pp. 54-59. doi:10.1016/j.hydromet.2006.04.005 